\title{
Noortje Marres (forthcoming, March 2017) Digital Sociology: The reinvention of social research. Cambridge: Polity Press.
}

\author{
Brit Ross Winthereik \\ brwi@itu.dk
}

In Digital Sociology Noortje Marres invites us to ponder over the impact of social media research on sociology and over how sociology is transformed by digital research methods. She does this by opening up a conversation with classic voices in sociology, Durkheim, Weber, Garfinkel, and others, whereby she offers insights into some of the methodological roots of digital methods. The book is guided by a desire to explore and clarify what research, with and against digital infrastructures might mean for contemporary sociology, media studies and STS. One of the central tenets is that innovation in big data and computational social science needs sociology's capacity for methodological innovation.

In the book, digitized social research is exemplified through cases and research conducted by Marres and colleagues over the past 5-8 years. Descriptions of to teaching situations and workshops offer lightness and liveliness to the theoretical argument. Only little is presented with regards to specification on how to design or carry out digitized social inquiry. Still, Digital Sociology comes across as a practical book, which is quite an achievement given its theoretical ambition. This is clearly an effect of Marres' capacities as a writer and of her skill in bringing digital technologies to life in text. But the book's practice-orientation touches on a more profound issue. To this reader it is a 'factoid' (Haraway, 2015) of social research of infrastructures more generally.
Digital infrastructures are recursive in the sense that they are simultaneously social phenomena worth of exploration and offer means of researching such phenomena (see also Jensen and Winthereik, 2013). Thus, we are required to work with their embedded capacities and shortcomings and make them into research tools and objects of inquiry. This is not unlike ethnography where the means of achieving knowing about sociality hinge on skills that are themselves 'social', like conversation and observation.

Conceptually, Marres specifies social research with and against digital infrastructures as interface methods. Rather than a set of methodological guidelines, interface methods is an approach that recognizes how, in the words of Marres:

important social research methods are already built into digital infrastructures, devices and practices, even if they currently tend to serve other-thansociological ends (2017: 13).

She argues that it is the non-trivial task of social theorists to

test and develop the capacities of these methodsdevices for social inquiry, so that they may better serve its purposes. While digital architectures constrain social research in many ways, they are also to an extent configure-able: the digital application of method requires a continuous mutual adjustment of research question, data, technique, context and digital setting. (2017: 13.) 
Interface methods are presented as a practical-theoretical instantiation of a device-aware sociology. Such device-awareness offers substantive insight into how digital infrastructures and other mundane instruments both persistently participate in contemporary social life and must be allied with to know about sociality.

And questions of epistemology and epistemic practices are pivotal for Marres. How to know digital methods? How to know about the controversies they have spurred, their publics, their histories, and the ends to which they have been put, their politics? The book offers comprehensive answers to such questions. It makes the point, repeatedly and in varied ways, that there is no way around technology for sociology. One of the most clearly stated points is that the reason for this is that technology problematizes the social in way that can be transformative for critical thinking. Technology, and digital infrastructure specifically, problematizes knowledge, sociality and politics.
Investigating the knowledge dimension of digital social inquiry, Marres (2017: 217) argues, brings into focus a much wider potential transformation of digital social life and social research than what can be contained in issues we recognize as ethical, legal and social. Thus, technical apparatuses of social life and social research must be specified for us to be able to critically scrutinize them. To explore the medium-specificity of digital societies, experimental and uncanny methods are needed as they may help us see the social at one and the same time both ordered and emerging

One direction in which this reader would like to explore further, with Digital Sociology firmly stuck into the travel pack, is how to better describe and re-narrate online data with ethnographic sensibility, in order to build an audience, and let the ethnographic exploration with and against digital infrastructure continue into writing. Unlike any other book in the field Digital Sociology offers a license to conjure up sociological objects of research with digital actors, that busy themselves with knowledge, sociality and politics.

\section{References}

Haraway D (2015) Anthropocene, Capitalocene, Plantationocene, Chthulucene: Making Kin. Environmental Humanities, 6, 159-165.

Jensen CB, \& Winthereik, BR (2013) Monitoring movements in development aid : recursive partnerships and infrastructures. Cambridge, Massachusettes: The MIT Press. 